\section{Fecal Calprotectin in Children with the Enthesitis-related Arthritis Subtype of Juvenile Idiopathic Arthritis}

\section{To the Editor:}

Subclinical gut inflammation is present in two-thirds of adult and pediatric patients with spondyloarthritis $(\mathrm{SpA})^{1,2}$ and predicts a chronic course of arthritis ${ }^{2,3}$. Thus, there may be value in evaluating the gut in patients with SpA. However, commonly used tests, such as colonoscopy, barium studies, and computed tomography, are limited by expense, invasiveness, or radiation exposure ${ }^{4}$, prompting a need for noninvasive surrogate markers. Serologic markers revealed a large number of false-positive tests ${ }^{5}$.

Fecal calprotectin is a sensitive and specific marker for the presence of inflammatory bowel disease or other intestinal illnesses ${ }^{6}$. This test has not heretofore been used to assess for subclinical gut inflammation in patients with arthritis. In this study, we measured fecal calprotectin levels in children with enthesitis-related arthritis (ERA), comparing them to children with non-SpA subtypes of juvenile idiopathic arthritis (JIA), as well as children with unrelated connective tissue diseases (CTD) and noninflammatory control subjects.

We enrolled 4 groups of children: (1) 9 with the ERA subtype of JIA; (2) 17 with other subtypes of JIA [persistent oligoarticular, $n=6$; extended oligoarticular, $\mathrm{n}=1$; rheumatoid factor-negative (RF-) polyarticular, $\mathrm{n}=8 ; \mathrm{RF}+$ polyarticular, $\mathrm{n}=2 \mathrm{]}$; (3) 9 with unrelated CTD (dermatomyositis, $\mathrm{n}=3$; localized scleroderma, $\mathrm{n}=5$; microscopic polyangiitis, $\mathrm{n}=$ 1); and (4) 6 noninflammatory control subjects (e.g., hypermobility syndrome). All children with JIA met the International League of Associations for Rheumatology criteria ${ }^{7}$. All children with ERA met the criteria on the basis of a history of arthritis in an HLA-B27+ boy with onset after the 6th birthday; additional $\mathrm{SpA}$ features included clinically diagnosed enthesitis in 2 , sacroiliitis in 3, family history in 2 , and acute anterior uveitis in one. We excluded children with acute onset $(<30$ days) of gastrointestinal (GI) symptoms as well as those with prior abnormal studies of the GI tract. We defined GI symptoms as being one or more of a history of chronic abdominal pain that interfered with activity, hematochezia, persistent diarrhea, or poor growth ${ }^{8}$. Active arthritis was defined by having at least one joint with swelling or limitation accompanied by joint pain or tenderness ${ }^{7}$. For chil- dren with unrelated CTD, disease activity was assessed clinically by the attending physician. Each enrolled child submitted a stool specimen for measurement of calprotectin; the specimen was provided on the day of the visit, hand-delivered to the hospital, or shipped overnight to the hospital by a commercial carrier. This study was approved by the Institutional Review Board at University of Texas Southwestern Medical Center. Informed consent was obtained from each subject's legal guardian, and assent was obtained in children age 10 years or older.

At the clinical laboratory, stool specimens were aliquoted into transport media provided by a commercial laboratory (ARUP, Salt Lake City, UT, USA) and were stored at $-25^{\circ} \mathrm{C}$ and shipped frozen overnight to ARUP for measurement of calprotectin, performed using ELISA. Calprotectin is stable at room temperature for up to 7 days ${ }^{9}$.

Calprotectin was measured on a continuous scale. Comparisons between the groups were made with the Kruskal-Wallis test. Values were also dichotomized to $<121 \mu \mathrm{g} / \mathrm{g}$ or $\geq 121 \mu \mathrm{g} / \mathrm{g}$, the cutoff suggested by ARUP. Comparisons of the dichotomized values were performed by chi-squared test.

The patient population is described in Table 1. GI symptoms were reported in 2 patients with ERA (abdominal pain and loose stools in one; abdominal pain and weight loss in another) and in one patient with polyarticular JIA (chronic poor weight gain).

Fecal calprotectin levels are shown in Table 1 and Figure 1. Median levels were highest in the children with ERA, and lowest in the CTD controls $(p=0.034)$. Among patients with ERA, nonsteroidal antiinflammatory drug (NSAID) use was not associated with an elevated fecal calprotectin level $(125 \mu \mathrm{g} / \mathrm{g}$ in NSAID users vs $201 \mu \mathrm{g} / \mathrm{g}$ in NSAID non-users; $\mathrm{p}=$ 1.000). Of the 3 patients who reported GI symptoms, 2 (1 ERA, 1 polyarticular JIA) had normal calprotectin levels, while 1 ERA patient had a calprotectin level of $310 \mu \mathrm{g} / \mathrm{g}$. The majority of ERA patients, but a minority of patients in each of the other groups, had abnormal levels $(\mathrm{p}=0.024$; Table 1).

The primary implication of this study is that a safe and noninvasive test can be used to evaluate for subclinical gut inflammation in arthritis patients. In addition, we confirm prior studies showing evidence of gut inflammation in children with $\mathrm{SpA}^{2}$.

Table 1. Study subjects.

\begin{tabular}{|c|c|c|c|c|c|}
\hline Characteristic & $\begin{array}{c}\text { Noninflammatory } \\
\text { Controls }\end{array}$ & CTD Controls & JIA Controls & ERA & $\mathrm{p}$ \\
\hline $\mathrm{N}$ & 6 & 9 & 17 & 9 & - \\
\hline Age, $\mathrm{yrs}^{\dagger}$ & $3.8(3.0-9.6)$ & $11(8.0-14)$ & $6.2(2.8-11)$ & $12(9.5-14)$ & 0.014 \\
\hline Female, $\%$ & 67 & 56 & 82 & 0 & 0.001 \\
\hline Ethnicity, \% & & & & & 0.070 \\
\hline Latino & 17 & 56 & 12 & 0 & \\
\hline Non-Latino White & 67 & 33 & 82 & 67 & \\
\hline African American & 17 & 0 & 6 & 22 & \\
\hline Other & 0 & 11 & 0 & 11 & \\
\hline \multicolumn{6}{|l|}{ Treatment, $\%$} \\
\hline NSAID & 33 & 0 & 65 & 56 & 0.013 \\
\hline Systemic corticosteroid & 0 & 33 & 0 & 11 & 0.042 \\
\hline Methotrexate & 0 & 78 & 65 & 56 & 0.019 \\
\hline Etanercept & 0 & 0 & 5.9 & 33 & 0.055 \\
\hline Other DMARD* & 0 & 33 & 0 & 0 & 0.009 \\
\hline Active disease & 0 & 67 & 100 & 78 & $<0.001$ \\
\hline GI symptoms, $\%$ & 0 & 0 & 5.9 & 22 & 0.242 \\
\hline Fecal calprotectin, $\mu \mathrm{g} / \mathrm{g}$ (range) $)^{\dagger}$ & $80(28-120)$ & $26(0-38)$ & $51(36-98)$ & $171(34-280)$ & 0.034 \\
\hline Fecal calprotectin, $>120 \mu \mathrm{g} / \mathrm{g}, \%$ & 17 & 11 & 18 & 67 & 0.024 \\
\hline
\end{tabular}

$\dagger$ Continuous data are presented as medians (intraquartile range). * One patient was taking mycophenolate, another was taking both mycophenolate and hydroxychloroquine, and a third was taking 6-mercaptopurine. DMARD: disease-modifying antirheumatic drug; CTD: connective tissue disease; ERA: enthesis-related arthritis. 


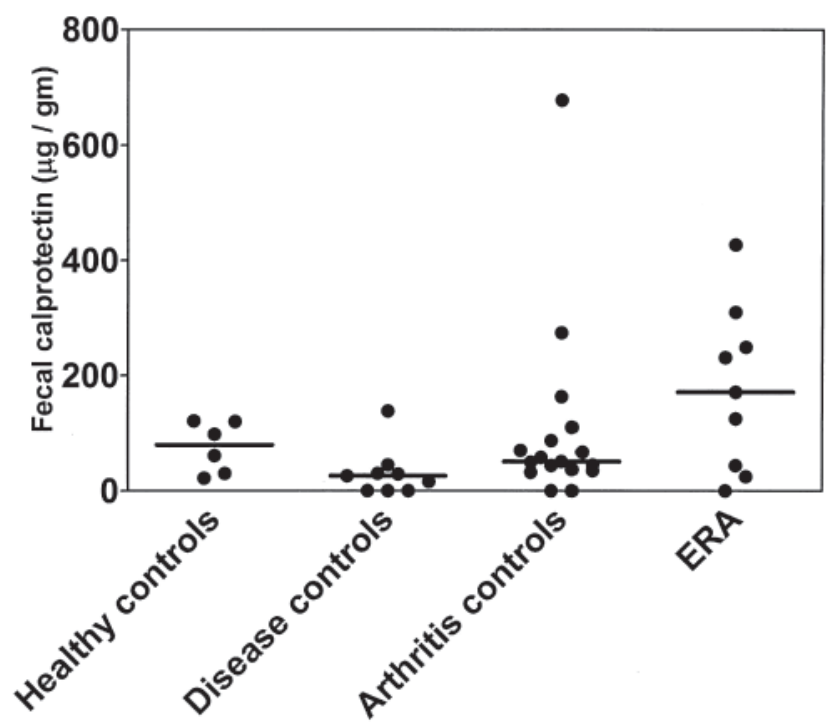

Figure 1. Calprotectin levels in children with enthesis-related arthritis (ERA), arthritis controls (oligoarticular and polyarticular juvenile idiopathic arthritis), noninflammatory controls, and disease controls (unrelated CTD).

Our study has several limitations. Our sample size was relatively small, and reflected patients who were heterogeneous with respect to treatment. Several patients with JIA were receiving NSAID, which could potentially have influenced the fecal calprotectin levels ${ }^{10}$; however, no clear association was observed in this study. Additionally, although fecal calprotectin is stable for up to 7 days at room temperature ${ }^{9}$, several specimens were shipped to us over the summer, when temperatures in Texas exceeded room temperature. The possibility for selection bias exists, in that patients with GI symptoms may have been more likely to participate in the study. However, no obvious relationship was observed between GI symptoms and calprotectin levels. All subjects with ERA were male, introducing a potential confounding factor. However, levels were similar between male and female patients in each of the other groups (data not shown), suggesting that gender is not likely to be an independent predictive factor. Additionally, all of the ERA patients were HLA-B27+, potentially indicating a higher risk of developing ankylosing spondylitis in the future, and thus may not be reflective of all patients with ERA. Finally, fecal calprotectin levels were obtained at a single timepoint only.

We show for the first time that stool biomarkers may be used to evaluate for intestinal inflammation in children with JIA. Future studies should be performed using validated "gold standard" assessments to confirm the significance of elevated fecal calprotectin levels in this population, and also to define the role of routine assessments of fecal inflammation in children and adults with SpA.

MATTHEW L. STOLL, MD; MARILYNN PUNARO, MD, Department of Pediatrics, University of Texas Southwestern Medical Center, Department of Rheumatology, Scottish Rite Hospital for Children; ASHISH S.

PATEL, MD, Department of Pediatrics, UT Southwestern Medical Center, Dallas, Texas, USA.
Dr. Stoll was supported by the North and Central Texas Clinical and Translational Science Initiative, grant number UL1RR024982, (Milton Packer, MD, PI) from the National Center for Research Resources, a component of the National Institutes of Health (NIH) and NIH Roadmap for Medical Research.

Address correspondence to Dr. Punaro;

E-mail: Marilynn.Punaro@TSRH.org.

\section{ACKNOWLEDGMENT}

The authors thank the patients and families for participating in this study.

\section{REFERENCES}

1. Mielants H, Veys EM, Goemaere S, Goethals K, Cuvelier C, De Vos M. Gut inflammation in the spondyloarthropathies: clinical, radiologic, biologic and genetic features in relation to the type of histology. A prospective study. J Rheumatol 1991;18:1542-51.

2. Mielants H, Veys EM, Cuvelier C, De Vos M, Goemaere S, Maertens M, et al. Gut inflammation in children with late onset pauciarticular juvenile chronic arthritis and evolution to adult spondyloarthropathy - a prospective study. J Rheumatol 1993;20:1567-72.

3. Mielants H, Veys EM, Cuvelier C, De Vos M, Goemaere S, De Clercq L, et al. The evolution of spondyloarthropathies in relation to gut histology. III. Relation between gut and joint. J Rheumatol 1995;22:2279-84.

4. Sinha R, Nwokolo C, Murphy PD. Magnetic resonance imaging in Crohn's disease. BMJ 2008;336:273-6.

5. de Vries M, van der Horst-Bruinsma I, van Hoogstraten I, van Bodegraven A, von Blomberg BM, Ratnawati H, et al. pANCA, ASCA, and OmpC antibodies in patients with ankylosing spondylitis without inflammatory bowel disease. J Rheumatol 2010;37:2340-4.

6. Costa F, Mumolo MG, Bellini M, Romano MR, Ceccarelli L, Arpe $\mathrm{P}$, et al. Role of faecal calprotectin as non-invasive marker of intestinal inflammation. Dig Liver Dis 2003;35:642-7.

7. Petty RE, Southwood TR, Manners P, Baum J, Glass DN, Goldenberg J, et al. International League of Associations for Rheumatology classification of juvenile idiopathic arthritis: second revision, Edmonton, 2001. J Rheumatol 2004;31:390-2.

8. Wyllie R, Hyams JS, Kay M, editors. Pediatric gastrointestinal and liver diseases. 3rd ed. London: Elsevier; 2006.

9. Bunn SK, Bisset WM, Main MJ, Golden BE. Fecal calprotectin as a measure of disease activity in childhood inflammatory bowel disease. J Pediatr Gastroenterol Nutr 2001;32:171-7.

10. Tibble JA, Sigthorsson G, Foster R, Scott D, Fagerhol MK, Roseth A, et al. High prevalence of NSAID enteropathy as shown by a simple faecal test. Gut 1999;45:362-6.

J Rheumatol 2011;38:10; doi:10.3899/jrheum.110508 